\title{
How and when do big data investments pay off? The role of marketing affordances and service innovation
}

\author{
Luigi M. De Luca ${ }^{1}$ (D) - Dennis Herhausen ${ }^{2} \cdot$ Gabriele Troilo $^{3}$ - Andrea Rossi ${ }^{1,4}$ \\ Received: 16 September 2019 / Accepted: 16 July 2020 / Published online: 5 August 2020 \\ (C) The Author(s) 2020
}

\begin{abstract}
Big data technologies and analytics enable new digital services and are often associated with superior performance. However, firms investing in big data often fail to attain those advantages. To answer the questions of how and when big data pay off, marketing scholars need new theoretical approaches and empirical tools that account for the digitized world. Building on affordance theory, the authors develop a novel, conceptually rigorous, and practice-oriented framework of the impact of big data investments on service innovation and performance. Affordances represent action possibilities, namely what individuals or organizations with certain goals and capabilities can do with a technology. The authors conceptualize and operationalize three important big data marketing affordances: customer behavior pattern spotting, real-time market responsiveness, and data-driven market ambidexterity. The empirical analysis establishes construct validity and offers a preliminary nomological test of direct, indirect, and conditional effects of big data marketing affordances on perceived big data performance.
\end{abstract}

Keywords Big data technologies and analytics $\cdot$ Affordance theory $\cdot$ Marketing affordances $\cdot$ Service innovation $\cdot$ Big data performance $\cdot$ Industry digitalization

Electronic supplementary material The online version of this article (https://doi.org/10.1007/s11747-020-00739-x) contains supplementary material, which is available to authorized users.

Alina Sorescu served as Guest Editor for this article.

Luigi M. De Luca

delucal@ cardiff.ac.uk

Dennis Herhausen

dennis.herhausen@kedgebs.com

Gabriele Troilo

gabriele.troilo@sdabocconi.it

Andrea Rossi

rossia@cardiff.ac.uk

1 Cardiff University Business School, Colum Drive, CF10 3EU, Cardiff, Wales, UK

2 KEDGE Business School, Domaine de Luminy, 13009 Marseille, France

3 Bocconi University and SDA Bocconi, Via Bocconi, 8, 20136 Milan, Italy

4 Centrica Plc, 4, Callaghan Square, Tresillian Way, Cardiff CF10 5BT, Wales, UK
"There is nothing so practical as a good theory (Kurt Lewin)."

More and better customer data have long been marketers' holy grail when such information was scarce. Firms are now investing significant resources into big data technologies and analytics (BDTA), following the assumption that they may drive superior performance (Lambrecht and Tucker 2015), enable business transformation (Davenport and Bean 2019), and facilitate disruptive business model innovations (Sorescu 2017). This is particularly evident in the service industry, where BDTA are changing the nature of the customer-firm connection, thereby disrupting existing value propositions (Huang and Rust 2017). Yet, the accelerating rate of big data investments is not always matched by an increased quality and effectiveness of marketing decisions (Shah et al. 2012), and senior managers report mixed perceptions of the extent to which big data contribute to a firm's performance (Bean and Davenport 2019). ${ }^{1}$ Hence, developing a better understanding

\footnotetext{
${ }^{1}$ According to a recent survey of senior executives in Fortune 1000 and industry-leading US firms, $91.6 \%$ of companies are accelerating the pace of big data investments. However, only $62.2 \%$ report measurable results from these investments; $59.5 \%$ declare to drive innovation with data, $47.6 \%$ claim to be competing on data and analytics, and only $31 \%$ perceive themselves as a data-driven organization (Davenport and Bean 2019).
} 
of how big data investments can turn into a competitive advantage is a priority for scholars and practitioners alike (Marketing Science Institute 2018).

The current understanding of the process through which big data investments pay off emerges from three research streams. First, information systems (IS) scholars recently started to describe the organizational affordances enabled by big data investments (Dremel et al. 2020; Lehrer et al. 2018). Affordances are defined as possibilities for action offered by a given technology to a goal-directed actor with certain capabilities (Volkoff and Strong 2018). Relatedly, marketing scholars directed attention towards the revolutionary impact of digital service innovation for competitive advantage in data-rich environments. In fact, ubiquitous communications and big customer data lead to the emergence of better and more personalized services (Rust and Huang 2014), which firms can use to build deeper and more profitable customer relationships through data-driven marketing actions (Kumar et al. 2013; Marinova et al. 2017). Finally, studies from strategic management and IS, established a positive relationship between big data investments and organizational outcomes such as firm productivity (Müller et al. 2018), firm performance (Wamba et al. 2017), and firm value (Tambe 2014). The positive link between big data investments and performance is attributed to the competitive advantage brought about by BDTA unique resources and capabilities (Grover et al. 2018). In this study we integrate the key tenets from these three largely disconnected research streams into a single and coherent conceptual model, and subject it to a rigorous, empirical test. The contributions of our study compared to previous research are summarized in Table 1.

First, we conceptualize and operationalize three distinct big data marketing affordances, defined as specific marketing actions enabled by investments into BDTA. These are customer behavior pattern spotting, real-time market responsiveness, and data-driven market ambidexterity. In doing so, we contribute to the nascent big data affordances literature by developing new scales for big data marketing affordances, and complementing existing case study evidence with the first quantitative examination of affordance-based hypotheses in both marketing and IS research. Second, we identify big data marketing affordances as antecedents of service innovation. Indeed, the central role of service innovation was conceptually argued in previous research on data-driven marketing (Rust and Huang 2014). Our findings add to this work by empirically testing the relationships between big data marketing affordances and service innovation, and differentiating among direct, indirect, and conditional effects of big data marketing affordances on perceived big data performance. Third, we add to research on the relationship between big data investments and performance by simultaneously accounting for big data marketing affordances and service innovation, against previous literature that focused on the direct effects of big data investments (Wamba et al. 2017), and identify industry digitalization as a boundary condition for the effect of big data investments on perceived big data performance.

To balance conceptual rigor and managerial relevance, our work is grounded in the marketing context and validated with marketing decision-makers. A key assumption within marketing strategy research is that structured data on customers, competitors, and the market environment are intentionally collected and analyzed, following predetermined market research techniques and analytical tools, to serve premeditated information needs and organizational goals. None of these assumptions holds its validity in the case of BDTA (Balducci and Marinova 2018). Our affordance-based perspective complements the extant body of knowledge built around market intelligence and market orientation - the intentional and predetermined acquisition, dissemination, and use of structured market data for premeditated information needs - to offer a reference point shift for marketing decision-makers involved with BDTA.

Our study is articulated as a scale development followed by a rigorous test of the scales' nomological validity (i.e., Homburg et al. 2015; Kuehnl et al. 2019). In line with this design, we first introduce the study's conceptual background. Next, we empirically validate the conceptual and practical relevance of our three big data marketing affordances, and then develop new scales to measure them (Study 1). Building on this scale development effort, we test the nomological network of big data marketing affordances, service innovation, and perceived big data performance, including the contingency role of industry digitalization (Study 2). We use data from interviews and multiple surveys with more than 400 managers from two countries, and proactively address potential sources of endogeneity (Rutz and Watson 2019).

\section{Conceptual background}

\section{Big data technologies and analytics}

Big data are described as large-volume, high-velocity, and heterogeneous data that emerge from the increasing digitization of transactions, interactions, communications, and everyday experiences (McAfee et al. 2012). Big data technologies include data management technologies that enable several key processes (Gandomi and Haider 2015): acquisition and recording; extraction, cleaning and annotation; integration, aggregation, and representation. Big data analytics make it possible to model, analyze, and interpret big data (Gandomi and Haider 2015). Big data analytics are often described in terms of their approach and contribution to decision-making (i.e., descriptive, diagnostic, predictive, and prescriptive; Wedel and Kannan 2016), and based on their specific use domain (i.e., text, speech, web, network, and mobile analytics; Chen et al. 2012). Thus, BDTA encompass the whole process of turning big data into valuable insights, which goes through 
Table 1 Summary of our contributions compared to existing research

\begin{tabular}{|c|c|c|c|c|c|}
\hline Theme & Key studies & Methods & Key findings & Limitations of existing studies & Contributions of our study \\
\hline $\begin{array}{l}\text { Big Data } \\
\text { Affordances }\end{array}$ & $\begin{array}{l}\text { Dremel et al. } \\
\text { (2020), Lehrer } \\
\text { et al. (2018) }\end{array}$ & $\begin{array}{l}\text { Conceptual } \\
\text { and } \\
\text { qualitative }\end{array}$ & $\begin{array}{l}\text { Big data technologies and } \\
\text { analytics generate new } \\
\text { affordances (i.e. } \\
\text { possibilities for actions) for } \\
\text { innovative service } \\
\text { provision. Firms that } \\
\text { successfully actualize big } \\
\text { data affordances can access } \\
\text { a new repertoire of service } \\
\text { innovation opportunities } \\
\text { and achieve a competitive } \\
\text { advantage. }\end{array}$ & $\begin{array}{l}\text { Narrow focus on } \\
\text { technological affordances, } \\
\text { while marketing } \\
\text { affordances are not } \\
\text { investigated. Evidence is } \\
\text { qualitative and limited to a } \\
\text { small number of case study } \\
\text { organizations. }\end{array}$ & $\begin{array}{l}\text { Scale development process to } \\
\text { conceptualize and } \\
\text { operationalize big data } \\
\text { marketing affordances. } \\
\text { First quantitative test of the } \\
\text { affordance theory } \\
\text { hypotheses in both } \\
\text { marketing and information } \\
\text { systems literature. }\end{array}$ \\
\hline $\begin{array}{l}\text { Big Data and } \\
\text { Service } \\
\text { Innovation }\end{array}$ & $\begin{array}{l}\text { Barret et al. (2015), } \\
\text { Kumar et al. } \\
\text { (2013), } \\
\text { Marinova et al. } \\
\text { (2017), Rust and } \\
\text { Huang (2014), } \\
\text { Troilo et al. } \\
\text { (2017) }\end{array}$ & $\begin{array}{l}\text { Conceptual } \\
\text { and } \\
\text { qualitative }\end{array}$ & $\begin{array}{l}\text { Big data technologies and } \\
\text { analytics and data-rich en- } \\
\text { vironments are the engine } \\
\text { of a new generation of ser- } \\
\text { vice innovations based on } \\
\text { new service concepts, pro- } \\
\text { cesses and personalized } \\
\text { customer interfaces. } \\
\text { Service innovation transfers } \\
\text { the potential value of big } \\
\text { data investments into supe- } \\
\text { rior performance. }\end{array}$ & $\begin{array}{l}\text { Lack of empirical } \\
\text { differentiation among } \\
\text { data-enabled marketing an- } \\
\text { tecedents of service inno- } \\
\text { vation. Contributions are } \\
\text { mostly conceptual or based } \\
\text { on qualitative research. }\end{array}$ & $\begin{array}{l}\text { Identification of different } \\
\text { antecedents of service } \\
\text { innovation among big data } \\
\text { marketing affordances. } \\
\text { First quantitative test of the } \\
\text { mediating role of service } \\
\text { innovation in the process } \\
\text { connecting big data } \\
\text { marketing affordances to } \\
\text { performance. }\end{array}$ \\
\hline $\begin{array}{l}\text { Big Data and } \\
\text { Performance }\end{array}$ & $\begin{array}{l}\text { Brynjolfsson et al. } \\
\text { (2011), Grover } \\
\text { et al. (2018), } \\
\text { Gupta and } \\
\text { George (2016), } \\
\text { Mikalef et al. } \\
\text { (2019), Müller } \\
\text { et al. (2018), } \\
\text { Tambe (2014), } \\
\text { Wamba et al. } \\
\text { (2017) }\end{array}$ & $\begin{array}{l}\text { Conceptual } \\
\text { and } \\
\text { quantitative }\end{array}$ & $\begin{array}{l}\text { Investments in big data have a } \\
\text { positive impact on firm } \\
\text { productivity and } \\
\text { performance. The link } \\
\text { between big data and } \\
\text { competitive advantage is } \\
\text { explained by superior } \\
\text { resources and dynamic } \\
\text { capabilities. }\end{array}$ & $\begin{array}{l}\text { Resource-based theory and } \\
\text { dynamic capabilities offer a } \\
\text { traditional theoretical } \\
\text { explanation and operate at a } \\
\text { very strategic level. Limited } \\
\text { relevance/implications for } \\
\text { marketing managers. } \\
\text { Predominantly focused on } \\
\text { information technology re- } \\
\text { sources and capabilities, } \\
\text { and the main effect of big } \\
\text { data investments on perfor- } \\
\text { mance. Limited investiga- } \\
\text { tion of boundary condi- } \\
\text { tions. }\end{array}$ & $\begin{array}{l}\text { Adoption of a marketing } \\
\text { perspective, and } \\
\text { identification of big data } \\
\text { marketing affordances and } \\
\text { service innovation as the } \\
\text { process connecting big data } \\
\text { investments to } \\
\text { performance. Digitalization } \\
\text { of industry is a boundary } \\
\text { condition for the } \\
\text { relationship between big } \\
\text { data investments, service } \\
\text { innovation, and perceived } \\
\text { big data performance. }\end{array}$ \\
\hline
\end{tabular}

managing structured and unstructured data, creating ad-hoc data structures, and using specialized analytical algorithms (Balducci and Marinova 2018).

\section{Affordance theory}

The key theory supporting our conceptualization is affordance theory. The origins of affordance theory track back to Gibson's (1979) work on the psychology of perceptions. According to this theory, goal-directed actors (i.e., animals, humans) interpret, relate to, and learn about objects in the environment (i.e., rocks, rivers, trees) in terms of the possibilities for action that these objects offer (i.e., their affordances), rather than by cognitively processing information on the physical characteristics inherent to the object and independent of the actor. For example, a tree can afford a bird to build its nest, a giraffe to eat, or a man to procure wood for burning or building. Thus, affordances depend on the relationship between actors' goals and abilities and the characteristics of objects within their environment (Chemero 2003). This relational property of affordances makes them dynamic: as the environment and the goals/abilities of actors change over time, new affordances emerge, and old ones cease to exist.

IS scholars translated the concept of affordance to study the impact of technology on organizational design and performance (e.g., Hutchby 2001; Strong et al. 2014; Zammuto et al. 2007). At its core, the IS affordance perspective advances that technologies offer possibilities for action that emerge from their interaction with organizational actors, processes, structures, systems, and goals. An affordance is actualized when an actor realizes its potential for action. For an affordance to exist, it is not necessary for an actor to have 
actualized it, however an actor who could actualize the affordance must exist (Strong et al. 2014). Thus, a technology may offer many affordances, but only a subset of these may be actualized at any given point in time.

While the affordance theory lens can be applied at multiple levels of analysis (e.g., individual versus organizational), the emphasis of recent research has been on organizational affordances, defined as "the extent that the potential actions enabled are associated with achieving organizational-level concrete outcomes in support of organizational-level goals" (Strong et al. 2014, p. 74). For example, Zammuto et al. (2007) provide five examples of organizational affordances offered by information technologies: work process visualization, real-time innovation, virtual collaboration, mass collaboration, and simultaneous synthetic representation. More recent contributions shed light on new organizational affordances offered by BDTA: Lehrer et al. (2018) use qualitative case studies to conceptually describe two important clusters of big data affordances in service companies: service automation and human-machine service practices; Dremel et al. (2020) analyzed four big data affordances for automotive companies: establishing customer-centric marketing, provisioning vehicle-data-driven services, data-driven vehicle developing, and optimizing production processes.

\section{Big data marketing affordances}

In line with affordance theory, we define big data marketing affordances as actualized possibilities to perform specific marketing actions offered by BDTA, which could not be realized otherwise. While affordance theory has not been explicitly recognized within the marketing literature so far, several studies of the impact of BDTA on marketing activities make direct reference to marketing affordances (e.g., Erevelles et al. 2016; Germann et al. 2014; Rust and Oliver 2000; Sleep et al. 2019; Troilo et al. 2017; Wedel and Kannan 2016). Drawing on these previous conceptualizations and examples, we introduce three primary big data marketing affordances: customer behavior pattern spotting, real-time market responsiveness, and datadriven market ambidexterity. These affordances capture marketing actions enabled by BDTA for specific actor/time/space combinations (Lycett 2013). Thus, we define big data marketing affordances as actualized organizational affordances. This distinction is crucial because while affordances represent a mere potential for action, actualized affordances relate to specific actions that have taken place to produce organizationallevel concrete outcomes (Strong et al. 2014).

Customer behavior pattern spotting The first big data marketing affordance, customer behavior pattern spotting, captures the extent to which BDTA afford companies the ability to spot and predict patterns of customer behavior that would not be easily detectable otherwise. This affordance may lead to the identification and implementation of effective marketing responses to both desirable and non-desirable customer behaviors. Customer behavior pattern spotting is an essential contribution of BDTA to marketing actions, which does not depend of previous knowledge or hypotheses, as it predominantly concerns the "know what" rather than the "know why" of customer behavior (Erevelles et al. 2016). For example, Germann et al. (2014) describe how Walmart used BDTA to detect a sharp rise in Pop-Tarts sales shortly before a hurricane, or NFLShop.com identified an increasing trend of online purchases from women buyers in the Holiday season.

Real-time market responsiveness Well before big data became a buzzword, Rust and Oliver (2000) anticipated the concept of real-time marketing as the new dominant paradigm for many service and product markets. Real-time marketing is based on the ability of marketers to satisfy the different and evolving needs and preferences of individual customers as and when they emerge (i.e. in specific actor/time/space contexts). More recently, Wedel and Kannan (2016, p. 102) described "the development of models to generate diagnostic insights and support real-time decisions from big data" as imminent. Real-time marketing works when companies embed customized offerings in 'decentralized 'intelligence' capable of anticipating or reacting to customer needs, either overtly or covertly, or to environmental changes" (Rust and Oliver 2000, p. 54). Marinova et al. (2017) argued that the combination of big data streams, smart technologies, and analytical techniques can generate arrays of data-driven options for real-time marketing action, which complement or substitute the interaction between customers and front-line employees. In fact, BDTA make it possible to minimize response time latency, defined as the temporal separation between an event and the response to that event, by reducing the intervals between data capture/ analysis/interpretation and action (Pigni et al. 2016). In line with this literature, we define real-time market responsiveness as the extent to which BDTA afford companies the ability to analyze events, make-decisions and enact a market response with minimal response time latency. For example, using live patient data and heart attack incidences over time, a smart medical device firm can predict in real-time when a patient is about to have a heart attack and respond with a series of actions and messages targeted to market stakeholders, such as the patient, her doctors, and the emergency services nearby (Marinova et al. 2017).

Data-driven market ambidexterity Market ambidexterity means the ability to exploit current customers/markets while exploring new ones (Voss and Voss 2013). Previous studies suggest that BDTA are a powerful tool to leverage information on current customers and connect them to future customer needs and market opportunities (e.g., Erevelles et al. 2016; 
Huang and Rust 2017; Zuboff 2015). We refer to this affordance as data-driven market ambidexterity: the extent to which BDTA afford companies to identify synergies and connections between current and future customer needs, service offerings and strategic market opportunities that would not be established otherwise. BDTA make it possible for firms to access large volumes of various information about new customer needs and market domains more cheaply, and therefore reduce the traditional barriers associated to exploratory learning (March 1991). Thus, data-driven market ambidexterity affords firms the visualization of new services that have synergies with their current offerings, customer needs, competitive conditions, and environmental trends. For example, Amazon employs BDTA to constantly explore new business opportunities in complementary product categories, which can be developed internally or through MarketPlace partners; at the same time, the company uses BDTA to exploit its internal service process by targeting external customers with similar needs for information solutions (Amazon Web Services) or logistical solutions ("Fulfilled by Amazon").

\section{Service innovation}

The role of service innovation is central to understand the link between big data investments, big data marketing affordances, and performance. As summarized by Rust and Huang (2014, p. 206): "Increasingly, and inevitably, all of marketing will come to resemble to a greater degree the formerly specialized area of service marketing, only with an increased emphasis on marketing analytics". In line with previous studies, we conceptualize service innovation across three dimensions: service concept, service process, and customer experience (Barrett et al. 2015; Den Hertog 2000; Miles 2008). ${ }^{2}$ New service concept refers to new ways to organize a solution to customer needs or problems, service process innovation consists of new or enhanced internal systems to deliver services to customers more efficiently, and customer experience innovation captures innovative firm-customer interfaces (i.e., touchpoints) that improve service interactivity and customization. Importantly, the notion of service innovation is not limited to the traditional services industries but is equally salient for the servitization of product-based strategies and business models (Barrett et al. 2015).

\footnotetext{
2 Though we defined service innovation dimensions separately, in line with the literature (e.g., Barrett et al. 2015; Den Hertog 2000), they are intertwined, and service innovations typically involve more than one dimension. For example, the introduction by major supermarkets of the scan-as-you-shop system is predominantly a customer experience innovation nested within an existing service concept, while the launch of the Amazon Go no-cashiers outlets introduced a new service concept. Both examples though, involve significant service process innovations.
}

\section{Study 1: Developing scales for big data marketing affordances}

\section{Rationale of the scale development process}

As big data affordances are possibilities for action offered by BDTA to organizations, their number is potentially indefinite, as firms' goals, capabilities, and competitive contexts are various and constantly changing (Majchrzak and Markus 2013). For this reason, affordance theory research typically targets sub-sets of affordances with a highly granular approach that captures the relevant possibilities for action within a given actor/time/space frame (Dremel et al. 2020; Lehrer et al. 2018; Majchrzak and Markus 2013; Strong et al. 2014).

In line with the need for a granular analysis, our aim was to identify a workable set of relevant big data marketing affordances for firms operating in today's competitive environment that could provide a parsimonious yet comprehensive basis for our theorizing and empirical analyses. Existing work on technological affordances in organizations is either conceptual (e.g., Majchrzak and Markus 2013; Volkoff and Strong 2018) or based on case study evidence (e.g., Dremel et al. 2020; Lehrer et al. 2018), and no previous study focused on BDTA from a marketing affordances perspective. For these reasons, we could not rely on existing scales for measuring big data marketing affordances. We therefore developed new scales, which cover the dimensionality we derived conceptually, and are parsimonious with respect to the number of items for each dimension. In line with prior research (e.g., Homburg et al. 2015; Kuehnl et al. 2019), we followed established scaledevelopment procedures (e.g., Churchill Jr. 1979; Gerbing and Anderson 1988). Table 2 shows the seven steps in our scale-development process.

\section{Validation of the big data marketing affordances (Study 1a)}

The first step in our scale development process was the validation of the three focal big data marketing affordances that we conceptually derived from previous literature (e.g., Erevelles et al. 2016; Pigni et al. 2016; Rust and Oliver 2000; Sleep et al. 2019; Troilo et al. 2017). To this aim, we first conducted six interviews with senior managers with extensive knowledge of BDTA, to gather their views on the relevance and validity of our three big data marketing affordances, to receive feedback on their conceptualization and definitions, and to solicit examples. This initial evidence suggested that managers recognize the face validity of our three big data marketing affordances, and can provide relevant examples (see Web Appendix 1). Also, these interviews did not indicate that we omitted important big data marketing affordances. 
Table 2 Overview of the scale development process for big data marketing affordances

\begin{tabular}{|c|c|c|}
\hline Process steps & Data and methods & Results \\
\hline 1. Conceptualization & $\begin{array}{l}\text {-Literature review } \\
\text {-Qualitative interviews with six managers (Study 1a): Example } \\
\text { quotes for the three big data marketing affordances in Web } \\
\text { Appendix } 1 \\
\text {-Survey with } 53 \text { managers to empirically validate the three big data } \\
\text { marketing affordances (Web Appendix 2) }\end{array}$ & Identification of three big data marketing affordances \\
\hline $\begin{array}{l}\text { 2. Item pool } \\
\text { generation }\end{array}$ & $\begin{array}{l}\text {-Literature review } \\
\text {-Interviews with } 40 \text { managers in seven service firms: Example } \\
\text { quotes for individual items in Table } 3\end{array}$ & Initial set of 45 items \\
\hline 3. Item reduction & $\begin{array}{l}\text {-Face validity check with three academics and two data scientists } \\
\text {-Survey data collection (Study } 1 \mathrm{~b} \text { ) } \\
\text {-Statistical procedures (EFA, CFA) }\end{array}$ & $\begin{array}{l}\text { Initial reduction from } 45 \text { to } 28 \text { items, further reduction } \\
\text { resulted in a final set of } 12 \text { items }\end{array}$ \\
\hline $\begin{array}{l}\text { 4. Scale } \\
\text { dimensionality }\end{array}$ & $\begin{array}{l}\text {-Discriminant validity: Fornell-Larcker criterion } \\
\text {-Comparison of different models with CFAs: Selection of the best } \\
\text { model based on fit indices }\end{array}$ & A three-factor model shows the best fit with the data \\
\hline $\begin{array}{l}\text { 5. Validation of the } \\
\text { final scale }\end{array}$ & $\begin{array}{l}\text {-Confirmation with statistical procedures (EFA, CFA) } \\
\text {-Additional data collection (Study 1c, Study 2) }\end{array}$ & $\begin{array}{l}\text { Results of the three-factor model validated with two addi- } \\
\text { tional data sets }\end{array}$ \\
\hline $\begin{array}{l}\text { 6. Discriminant } \\
\text { validity }\end{array}$ & $\begin{array}{l}\text {-EFA and CFA of big data marketing affordances and big data } \\
\text { availability, data-oriented culture, and marketing-IT collabora- } \\
\text { tion } \\
\text {-Fornell-Larcker criterion between the big data marketing } \\
\text { affordances and big data availability, data-oriented culture, and } \\
\text { marketing-IT collaboration }\end{array}$ & $\begin{array}{l}\text { Discriminant validity of big data marketing affordances } \\
\text { from big data availability, data-oriented culture, and } \\
\text { marketing-IT collaboration }\end{array}$ \\
\hline $\begin{array}{l}\text { 7. Nomological } \\
\text { validity }\end{array}$ & -Fig. 1 shows the conceptual model & $\begin{array}{l}\text { Big data investments increase service innovation and } \\
\text { perceived big data performance via big data marketing } \\
\text { affordances }\end{array}$ \\
\hline
\end{tabular}

Notes: $\mathrm{EFA}=$ exploratory factor analysis, $\mathrm{CFA}=$ Confirmatory factor analysis

Next, to corroborate these preliminary indications, we collected a short survey asking informants to report up to five marketing actions enabled by BDTA in their firms. We sent a link to an online survey to 200 marketing managers who attended executive education in one of the authors' business school, and obtained valid replies from 53 of them (26.5\% response rate). We collected a total of 121 entries, for an average of 2.3 marketing actions per informant. We asked two doctoral students and one data scientist who were unfamiliar with our study to independently group responses that shared a common theme. Any diverging interpretation was discussed and reconciled. The top four themes obtained via this process ( $81 \%$ of all entries) largely overlap with our three big data marketing affordances and the service innovation constructs. Other themes include sales-related affordances ${ }^{3}(7.4 \%)$, and pricing-related affordances (2.5\%); the residual entries $(9.1 \%)$ are not underpinned by a single theme (Web Appendix 2). This evidence supports the parsimony and relevance of our three-affordance framework. Next, we generated an

\footnotetext{
${ }^{3}$ Though their incidence is lower than our focal affordances, sales-related affordances emerge here as an interesting area for future research. We acknowledge this point in the limitations and future research section.
}

initial item pool for the three big data marketing affordances.

\section{Item generation and initial reduction of items}

We employed two sources of information for item generation: a review of relevant conceptual literature (e.g., Erevelles et al. 2016; Pigni et al. 2016; Rust and Oliver 2000; Troilo et al. 2017; Wedel and Kannan 2016), and semi-structured interviews with 40 managers in seven large international service firms. ${ }^{4}$ From the review and the interviews, we generated an initial pool of 15 items for each of the three marketing affordances. Conscious of the need to make scales short enough to be usable in empirical research, we first shared the definitions of big data marketing affordances with three marketing faculty members and two data science practitioners, and asked them to assign each item to one of the three specific affordances. We conservatively excluded 17 items that did not receive a $100 \%$ consistent assignment, and further refined some items according to the experts' suggestions.

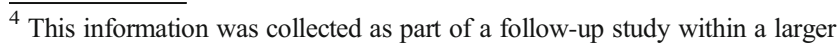
longitudinal research programme.
} 


\section{Reduction of the number of items (Study 1b)}

We submitted the remaining 28 items to a quantitative test with managers of 107 service firms from Italy in $2016 .{ }^{5}$ The initial sampling frame was obtained from Bureau van DijkAIDA, a dataset of all registered firms operating in the country. ${ }^{6}$ From an initial list of 8169 firms, we narrowed down to 263 firms that met two criteria: 1) they reported on their website current examples of big data projects and service innovations; 2) they had a company LinkedIn profile from which we could identify organizational roles linked to big data and innovation. A research assistant used LinkedIn to contact the selected informants. We obtained 122 responses (46\% response rate), and discarded 15 due to missing data. $53 \%$ of informants were IT managers, ${ }^{7} 12 \%$ marketing managers, $12 \%$ business development managers, $7 \%$ CEOs, $7 \%$ CIOs; the remaining $9 \%$ included product managers, innovation managers, and others. In line with Kumar et al. (1993), we checked for informants' knowledge ("How knowledgeable are you about the topics of the survey?"), involvement ("How involved are you with the activities and decisions mentioned in this survey?"), and confidence ("How confident are you in the quality of your responses to this survey?"). Informants scored high on 10-point scale ("1 = not at all"; "10 = a lot") regarding big data knowledge (mean = 7.75), involvement $($ mean $=6.90)$, and confidence $($ mean $=7.97)$.

\section{Scale parsimony and dimensionality}

To develop parsimonious scales, we chose the items with the highest indicator reliabilities for each dimension. The elimination of semantically similar items did not lead to a loss of content validity and reliability. Importantly, the model with the 12 remaining items achieved better goodness-of-fit values than the model with 28 items. ${ }^{8}$ Table 3 gives examples, for each item, of managerial quotes referring to customer behavior pattern spotting, real-time market responsiveness, and data-driven market ambidexterity from the interviews.

\footnotetext{
5 The items were generated in English and back translated by professional native speaker translators to Italian for Study $1 \mathrm{~b}$ and Study $1 \mathrm{c}$ and to German for Study 2 following established procedures.

${ }^{6}$ We restricted our initial sample to the following industries (NACE codes): utilities $(35,36)$, wholesale trade (46), postal services (53), TLC (61), computer programing (62), information services (63), financial services (64), insurance (65), legal services (69), consultancy (70), scientific R\&D (72), advertising and marketing research (73), employment support and business support (82), gambling and betting (92).

${ }^{7}$ IT managers are often directly involved with performing and/or managing data technologies, data analytics, and data science activities related to marketing projects, therefore they are knowledgeable about marketing affordances. The literature also recognizes the increasing influence of IT within marketing decision-making (Brinker and McLellan 2014; Sleep et al. 2019).

${ }^{8}$ Fit values for the 28 items are $\chi(347)=907.92, \mathrm{CFI}=.80, \mathrm{TLI}=.78$, RMSEA $=.12$, and SRMR $=.07$.
}

An exploratory factor analysis (EFA) with the final pool of 12 items revealed the three expected factors with eigenvalues greater than 1 (see Web Appendix 3). In line with our conceptualization, a confirmatory factor analysis (CFA) with the final 12 items confirms the three dimensions of customer behavior pattern spotting, real-time market responsiveness, and datadriven market ambidexterity (see Web Appendix 4). Specifically, standardized factor loadings were all high and significant $(p<.01)$ ranging from .72 to .97 . Moreover, the final three-factor model showed good global and local fit statistics: Satorra-Bentler corrected chi-square (degrees of freedom) $\chi(51)=109.58$, comparative fit index $(\mathrm{CFI})=.95$, Tucker-Lewis index $(\mathrm{TLI})=.93$, root mean square error of approximation $(\mathrm{RMSEA})=.10$, standardized root mean square residual $(\mathrm{SRMR})=.07$. The Cronbach's Alpha are $\geq$ .88 , and the average variance extracted (AVE) $\geq .66$. Examination of the Fornell-Larcker criterion, which requires that for every pair of factors the squared correlation should be smaller than each factor's AVE, revealed that discriminant validity exists for each of the three factors. Moreover, comparisons of models with different numbers of big data marketing affordances dimensions confirmed the best model fit for the three-factor solution. ${ }^{9}$ These findings corroborate the evidence from Study 1a in establishing the dimensionality of the three big data marketing affordances.

\section{Validation and discriminant validity (Study 1c)}

With Study 1c, we sought to validate the measurement properties of the three big data marketing affordances scales, using marketing and IT managers from various industries as key informants. In addition, we tested the discriminant validity of big data marketing affordances against three related big data constructs. The key is that affordances capture the actualized possibilities for action stemming from BDTA, in contrast to mere big data availability, or the presence of a dataoriented culture, and collaborative structures (i.e. marketingIT collaboration).

Data collection and measures The sampling frame for Study $1 \mathrm{c}$ consisted of 600 managers who attended executive education courses on data analytics, digital marketing, and/or service marketing at one of the authors' business school between 2014 and 2017. The alumni office of the business school

\footnotetext{
${ }^{9}$ Using a one-dimensional measure for big data marketing affordances led to a significantly lower fit $(\Delta \chi(3)=371.78, p<.01 ; \chi(54)=481.36, \mathrm{CFI}=.60$, $\mathrm{TLI}=.51$, RMSEA $=.27$, SRMR $=.12$ ), as did measures that combine customer behavior pattern spotting and real-time market responsiveness $(\Delta \chi(1)=142.99, p<.01 ; \chi(53)=252.57, \mathrm{CFI}=.81, \mathrm{TLI}=.77$, RMSEA $=.19$, SRMR $=.12$ ), customer behavior pattern spotting and datadriven market ambidexterity $(\Delta \chi(1)=145.50, p<.01 ; \chi(53)=255.08$, $\mathrm{CFI}=.81$, TLI $=.76$, RMSEA $=.19$, SRMR $=.14$ ), or real-time market responsiveness and data-driven market ambidexterity $(\Delta \chi(1)=278.5678$, $p<.01 ; \chi(53)=388.14, \mathrm{CFI}=.69, \mathrm{TLI}=.61, \mathrm{RMSEA}=.24, \mathrm{SRMR}=.16)$.
} 
Table 3 Item-by-item quotes from the manager interviews for the three big data marketing affordances

Indicator

Customer Behavior Pattern Spotting

PS1 Identify patterns of customer behavior across our touchpoints

PS2 Predict undesirable customer behaviors, such as for example complaints or churn

PS3 Predict desirable customer behaviors, such as for example propensity to buy or word-of-mouth

PS4 Identify patterns of competitive actions affecting our customers

Real-Time Market Responsiveness

RT1 Perform real-time analyses

RT2 Make real-time decisions

RT3 Implement real-time decision rules

RT4 Identify the best next action in customer interactions

Data-Driven Market Ambidexterity

MA1 Explore synergies with current offerings

MA2 Identify new strategic opportunities

MA3 Visualize the connection between current products/services and future ones

MA4 Identify synergies between current and future customer needs
Sample quote

The idea is to collect all information for each customer, such as usage, behavior and demographics across touchpoints, aggregate them, and use them for customer care, sales or whatever visualization need you have [Head of ICT Group Governance, Postal Services]

The first stage of our data modeling efforts is churn prevention... we want to be able to intercept customers who are likely to leave us so we can make some preventive action. [CTO, Telecommunication Services]

Outbound will use propensity models to identify which customers are likely to buy an additional product, and what additional product they are most likely to buy [Head of Outbound, Insurance Services].

We can perform very detailed analyses of customer churn by area, by channel... and spot if customers who leave us have been targeted by our competitors in any systematic way [Senior VP Sales, Petrol, Energy and Mobility Services]

Once you capture an information and analyze it in real time...OK say within $10 \mathrm{~min}$ if you are slow...your response will hit the target before everything has potentially changed (Head of Data Science, Utilities Services)

Marketing decision-making changes because our customers want quick and immediate answers, which are personalized and interactive, so it's crucial that we give real-time answers with customized content [Head of CRM, Financial Services]

... in March next year we'll launch on our portal a real-time decision engine linked to our analytics systems, so that our website will decide what to display to each customer based on real-time information, even including calls to our call center a minute earlier... [Senior VP Customer Management, Petrol Stations, Energy and Mobility Services]

When one of our operators receives a call, she should know what the best next action for that customer, based on some parameters... for example if we can sell extra services, and which one to propose first (Customer Services Executive VP, Utilities $\&$ Telecommunication Services)

....as an energy supplier we may decide to enter the market for home security and alarm systems, and use our big data to define the product, how to position it, what features the systems should have and so on...[Head of Digital Transformation Services, Utilities Services]

... with big data, the boundaries of a product or a service disappear, and you need to have a vision of what you are interested in. You never forget that customers want price, convenience and value but you then use data to identify opportunity zones that you could not identify before. [Head of Marketing, Financial Services]

So, actually, we know enough information about a customer to know potentially whether they're in the market for new services we may launch in the future [Head of Business Development, Insurance Services]

..by plugging a smart meter I can understand how a customer consumes energy today and anticipate her future needs...I can design a new bundle of 'energy management' services for the household, of which the energy bill is just one component. [Head of ICT, Operations and End User Services, Petrol, Energy and Mobility Services]

Notes: The quotes were obtained in semi-structured interviews with 40 managers from seven large international service firms

contacted the informants with a request to take part in the study, accompanied by a letter from the research team and a link to the web-survey. We received 135 responses $(22.5 \%$ response rate), 14 of which were discarded due to missing data or because informants reported that their confidence in the big data topic was 6 or less (on a 1-10 scale). Of the remaining 121 valid informants, 56\% were marketing managers and 44\% IT managers. ${ }^{10}$ Participants scored high on big data knowledge $($ mean $=7.03)$, big data involvement

\footnotetext{
${ }^{10}$ Informants belonged to the following industries (NACE): utilities $(35,36)$, wholesale trade (46), TLC (61), computer programing (62), information services (63), financial services (64), insurance (65), legal services (69), consultancy (70), scientific R\&D (72), advertising and marketing research (73), employment/business support (82).
} 
(mean $=6.43$ ), and confidence $($ mean $=7.26)$. To account for potential common method bias, we used a variety of scales, pretested the questionnaire, reassured respondents about anonymity and confidentiality, and emphasized that there were no right or wrong answers, to help reduce the likelihood of selfpresentation bias. We measured big data marketing affordances with the newly developed scales, big data availability based on the $3 \mathrm{~V}$ framework (Johnson et al. 2017; Laney 2001), data-oriented culture based on Davenport et al. (2012), and marketing-IT collaboration with a measure adapted from Kahn and Mentzer (1998). The Appendix reports all measurement items. An EFA reveals the six factors, and a CFA on all scales shows good fit indices $(\chi 2$ (d.f.) $=$ 360.70 (284); $p<.01 ; \mathrm{CFI}=.97$; TLI $=.97$; $\mathrm{RMSEA}=.05$; SRMR $=.05)$.

Discriminant validity We assessed whether the three big data marketing affordances are empirically distinct from the three related constructs. First, we compared the correlation between all six constructs with their AVEs. All pairwise correlations were smaller than the square root of the AVE for each construct (see Web Appendix 5). Further, combining any related construct with any of the big data marketing affordances significantly decreased the overall model fit (all $\Delta \chi(1)>147.32$, $p<.01$ ), indicating discriminant validity. Taken together, through Study 1a, Study 1b, and Study 1c we developed three new scales for big data marketing affordances, established scale dimensionality, and provided evidence for discriminant validity against related measures. Next, using new data, in Study 2 we further validate the newly developed scales (as reported in Web Appendix 3 and 4), and test their nomological validity in relation to a wider set of constructs, including antecedents, consequences and contingencies.

\section{Study 2: Testing the nomological network of big data marketing affordances}

In Study 2, we test the nomological network of big data marketing affordances. In doing so, we advance a set of hypotheses and provide preliminary empirical findings on the process linking big data investments and performance, which include indirect effects and boundary conditions. By investing in big data, firms create the conditions for the actualization of big data marketing affordances (i.e., new BDTA-enabled marketing actions). In line with affordance theory, big data marketing affordances improve a firm's ability to develop and introduce valuable service innovations (Lehrer et al. 2018). Finally, service innovation is linked to perceived big data performance, so that overall, there is a process from the initial big data investments to perceived big data performance, mediated by big data marketing affordances and service innovation. Finally, industry digitalization moderates the positive effect of service innovation on perceived big data performance (see Fig. 1).

\section{Hypotheses development}

We propose that big data investments positively affect customer behavior pattern spotting, real-time market responsiveness, and data-driven market ambidexterity. Following the key tenet of affordance theory, BDTA change the sociotechnical system of organizations, and interact with their capabilities and goals to enact specific new actions (Dremel et al. 2020). By investing in big data, firms actualize the three affordances for data-driven marketing as they become able to perceive the action possibilities offered by BDTA, experiment with such actions, socialize this experience across different teams and sub-units, and embed these actions in their structures and processes (Strong et al. 2014). Based on this logic, we expect that:

H1: Big data investments are positively related to (a) customer behavior pattern spotting, (b) real-time market responsiveness, and (c) data-driven market ambidexterity.

As described in the literature and anecdotally pictured in the examples above, big data marketing affordances widen the space for service innovation opportunities that firms can pursue in both the short and the long term (Davenport et al. 2012; Huang and Rust 2017; Rust and Huang 2014). Customer behavior pattern spotting and real-time market responsiveness are more likely to lead to short-term innovation opportunities, while data-driven market ambidexterity may produce more long-term innovation benefits. Customer behavior pattern spotting may lead to incremental service innovations that leverage superior knowledge of users' consumption patterns. For example, digital content may be reconfigured, customized, and/or prioritized based on customer behaviors. Also, real-time market responsiveness can lead to designing new service offerings that adapt and respond dynamically to the customer context, thereby providing timely and valuable new offerings and new customer experience. Finally, data-driven market ambidexterity may lead to new service concepts that leverage resource complementarities and other synergies for service innovations that only become apparent through BDTA. Thus, in line with affordance theory, we advance that the potential for service innovation that firms are able to afford via big data investments is realized via the three big data marketing affordances, such that:

H2: The effect of big data investments on service innovation is mediated by (a) customer behavior pattern spotting, (b) real-time market responsiveness, and (c) data-driven market ambidexterity. 
Fig. 1 Conceptual model for the nomological test of big data marketing affordances

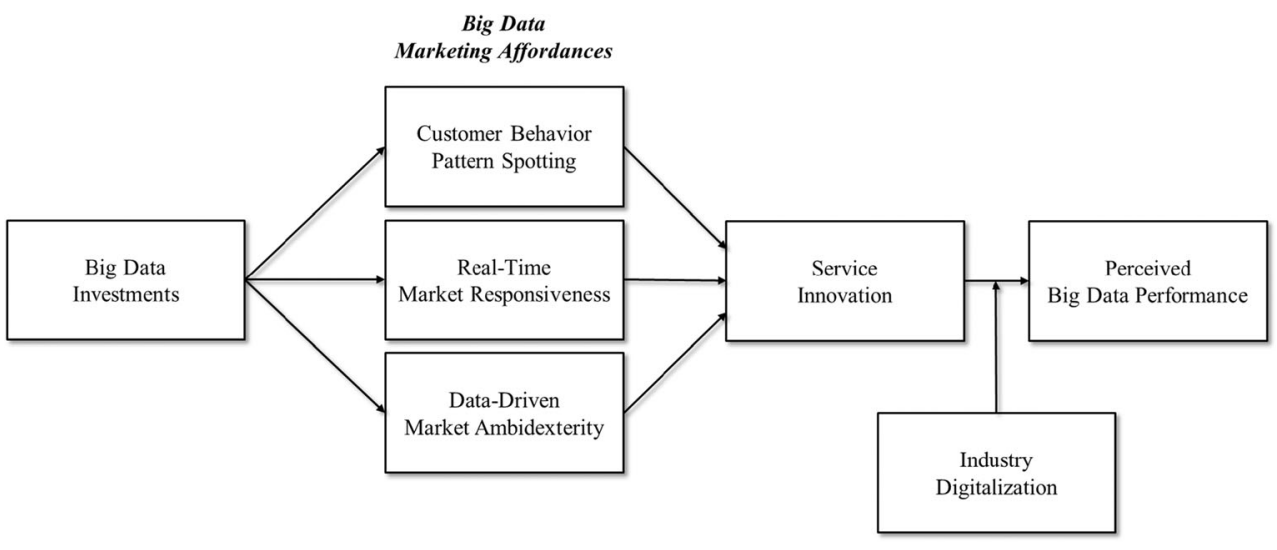

Previous research empirically supports a link between big data investments and firm performance (e.g. Müller et al. 2018; Wamba et al. 2017), but does not explore the intermediate processes accounting for this link. We hypothesize that the overall effect of big data investments on perceived big data performance is at least partially explained by service innovation and the big data marketing affordances. In line with previous research that proposed innovation as a mediator between outside-in capabilities, such as market intelligence, and performance (e.g., Han et al. 1998), we argue that big data marketing affordances generate more opportunities to use data in novel and useful ways to locate new service ideas. In turn, this enhances the firm's service innovation competence, such that the benefits of big data investments and related affordances accrue through the launch of new and successful services in the marketplace (Rust and Huang 2014). Taking these arguments together, we advance that:

H3: Service innovation mediates the effect of (a) customer behavior pattern spotting, (b) real-time market responsiveness, and (c) data-driven market ambidexterity on perceived big data performance.

H4: The effect of big data investments on perceived big data performance is mediated by (a) big data marketing affordances and (b) service innovation.

There is strong consensus in the marketing strategy literature that the relationship between firm innovativeness and firm performance is contingent on salient industry characteristics (e.g., Dotzel et al. 2013; Mizik and Jacobson 2003). In particular, cumulated empirical evidence exists that firms in high-tech industries benefit more from innovativeness than their low-tech industries counterparts (Rubera and Kirca 2012). Based on this established theoretical foundation, we examine the moderating role of industry digitalization between service innovation and perceived big data performance within our nomological network. Specifically, we expect the effect of service innovation on perceived big data performance to be stronger for firms competing in industries with a high (versus low) degree of digitalization, for two main reasons. First, when industry digitalization is high, customers will be more sensitive to offerings that embed a significant digital innovation element, and will adopt them faster, thus improving innovation returns (Rubera and Kirca 2012). Second, in such contexts, BDTA become a stronger driver of differentiation, and the presence of premium innovative offerings is more likely. In contrast, when industry digitalization is low, we expect the rewards from service innovation to be reduced, due slower customer adoption and weaker digital competition. In line with this argument, recent studies support the notion that firms in information technology-intensive industries extract more value from BDTA assets, than firms in less technologically developed industry groups (Müller et al. 2018; Tambe 2014). We also expect this contingency to qualify the indirect effect of big data investments on perceived big data performance.

H5a: The effect of service innovation on perceived big data performance is moderated by industry digitalization, such that the effect is stronger when digitalization is higher.

H5b: The indirect effect of big data investments on perceived big data performance via big data marketing affordances and service innovation is moderated by industry digitalization, such that the effect is stronger when digitalization is higher.

\section{Context and data collection}

We used data from a survey among 110 Swiss firms at two points in time, separated by four months in 2018 , to test our hypotheses. Big data investments and big data marketing affordances were measured at $\mathrm{T}_{1}$, and service innovation and perceived big data performance were measured at $\mathrm{T}_{2}$. We used a panel database of a professional marketing association to contact 707 senior managers responsible for marketing and/or marketing analytics with an invitation to an electronic survey. After one follow-up, we received 184 fully completed $\mathrm{T}_{1}$ 
questionnaires (26\% response rate) from managers working in various industries. ${ }^{11}$ Respondents have on average 8.54 years of experience with the firm, and score 6.11 on a seven-point scale measuring the degree of knowledge about big data processes in their firm. After four months, the 184 managers received a reminder and a gift certificate incentive, and 110 informants provided the requested information $\left(60 \% \mathrm{~T}_{2}\right.$ response rate). Participants scored high on big data knowledge (mean $=7.38$ ), involvement $($ mean $=6.69)$, and confidence $($ mean $=7.11)$.

In line with the recommendations from Hulland et al. (2018), we used multiple a priori methods for dealing with common method bias. Namely, we temporally separated the measures of dependent and independent constructs, we employed different response scales for different variables, used physical separation among related scales within the questionnaire, and we validated the subjective measure of big data investments with objective measures related to the number of dedicated big data employees newly employed and IT investment allocations. ${ }^{12}$

\section{Measurement}

The Appendix provides the measurement items for all constructs. We used the newly developed scales for big data marketing affordances and measured big data investments with three items tapping the extent to which firms invest resources in big data projects, consider big data as a priority in allocating resources, and invest in human talent for big data. These items emerged from our interviews and are consistent with the indicators of big data investments from the literature (McAfee et al. 2012; Wamba et al. 2017). We measured service innovation based on the three dimensions of service concept, service process, and customer experience (Barrett et al. 2015; Den Hertog 2000). We used a 3-item scale for each first-order factors, and aggregated them, with parceling, into a second-order factor capturing service innovation $(\chi 2$ (d.f.) $=54.63(24) ; p<.01$; $\mathrm{CFI}=.96 ; \mathrm{TLI}=.94 ; \mathrm{RMSEA}=.11 ; \mathrm{SRMR}=.07)$. We used a 5-item scale based on Wamba et al. (2017) to measure perceived big data performance (i.e., the organizational perceptions of the extent to which big data contribute to a firm's performance by generating a positive return on investments). In line with Edeling and Himme (2018), we adopted Gandhi et al.'s (2016) measure of industry digitalization to categorize industries from weakly

\footnotetext{
${ }^{11}$ Our informants are distributed across the following industries: finance and insurances $(17 \%)$, professional services $(12 \%)$, ICT $(10 \%)$, retail trade $(10 \%)$, industrial services $(9 \%)$, health care $(7 \%)$, advanced manufacturing $(5 \%)$, consumer services $(5 \%)$, utilities $(5 \%)$, media $(4 \%)$, hospitality $(3 \%)$, education $(2 \%)$, and others $(11 \%)$.

${ }^{12}$ We collected additional data on big data investment for the past two years from 51 managers. We then correlated the item "We hired a lot of new people to work with big data" with the number of dedicated big data employees newly employed during the past two years $(r=.57)$ and the item "Relative to our budget, we have invested a lot in big data projects" with the percentage of big data investments over the overall IT budget $(r=.56)$.
}

influenced (e.g., hospitality) to highly influenced (e.g., ICT) by digitalization on a six-point scale.

We controlled for several observed sources of heterogeneity across firms. Namely, we controlled for big data availability (e.g., Johnson et al. 2017) because the firm-specific availability of data might determine both big data marketing affordances and their outcomes; data-oriented culture (Davenport et al. 2012), because such culture could contribute to the effectiveness and efficiency of big data projects; and marketing-IT collaboration (Kahn and Mentzer 1998), because strategically involving the IT department within the marketing sphere fosters the successful implementation of BDTA projects within firms (Brinker and McLellan 2014; Sleep et al. 2019). To account for the impact of human capital and the key role of data scientists, we controlled for the number of data specialists. Finally, to account for industry and firm characteristics, we controlled for B2B versus B2C focus, for the proportion of pure services versus services including tangible goods in a firm's offering, and for firm size (employee number) and age. Table 4 reports descriptive statistics, correlations, Cronbach's alpha, and AVEs for all variables. A CFA on all multi-item scales indicated a good fit with the data $(\chi 2$ (d.f. $)=836.84(558) ; p<.01 ; \mathrm{CFI}=.94 ; \mathrm{TLI}=.92$; $\mathrm{RMSEA}=.05 ; \mathrm{SRMR}=.04)$.

\section{Model development}

Accounting for self-selection bias As we could only include firms in the analysis for which $\mathrm{T}_{2}$ data were available, our estimates may be biased due to a self-selection process (e.g., less successful firms choosing not to participate in the second survey). To address this issue, we employed a two-stage selection model. In the first stage, we estimated a choice model with the availability of $\mathrm{T}_{2}$ data as the binary dependent variable. From this model, we compute the inverse Mills ratio (IMR) to account for a potential selection bias.

Accounting for unobserved heterogeneity Beyond the observed covariates, unobserved factors could potentially influence perceived big data performance. For example, some firms might have a higher veracity in their data, or employees more open towards data-driven insights compared to other firms, yet we were not able to observe this. Not accounting for such unobserved factors can lead to statistically biased, inconsistent parameter estimates. To account for unobserved heterogeneity, we follow a semiparametric approach and represent the intercept term with a finite number of support points to account for heterogeneity across firms.

Accounting for endogeneity Additional concerns about endogeneity may arise because some variables that are omitted might influence both perceived big data performance and key explanatory variables. First, a firm's strategic choice to 


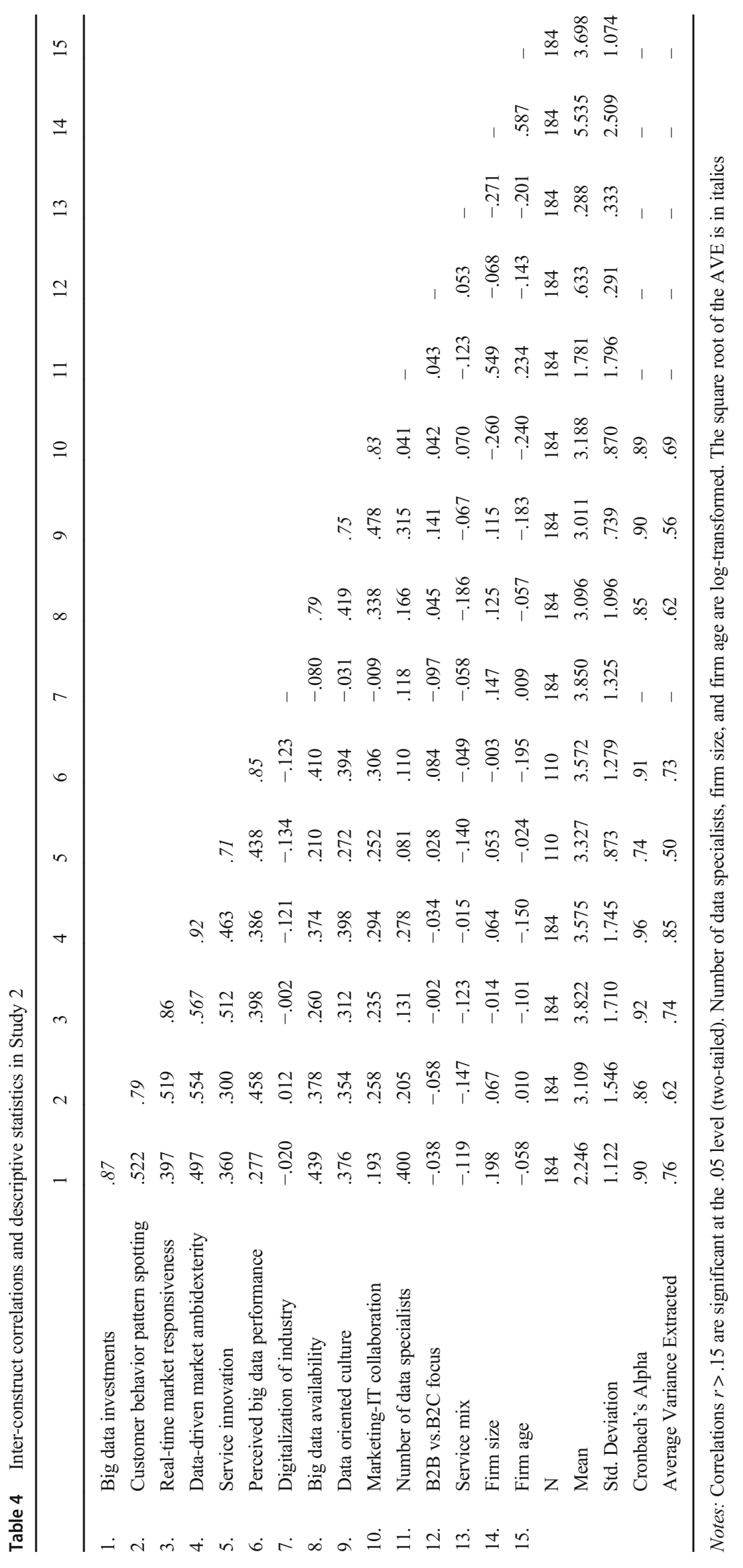


invest in big data is made in anticipation of future performance (Müller et al. 2018), thus big data investments could be endogenous. Second, all three big data marketing affordances depend on both firm decisions and the characteristics of the available data (Sleep et al. 2019), and the latter are unobservable for us. Third, service innovations not only depend on firms' decisions but also on consumer acceptance and competitive actions (Gielens and Steenkamp 2007). Such external forces are unobservable for us. As finding valid instruments was not feasible, we used the latent instrumental variable (LIV) approach as introduced by Ebbes et al. (2005). In line with Herhausen et al. (2020), we used a two-step approach where we first partition the variance of each endogenous regressor into an endogenous and an exogenous component, and then use both the endogenous and exogenous components as predictors in the main model (see Web Appendix 6).

\section{Model estimation and results}

Estimation strategy We started by estimating the IMR correction term to address the self-selection bias. The probit model in Web Appendix 7 shows acceptable fit indices (pseudo $\mathrm{R}^{2}=.20$; Wald $\chi 2=40.30, p>.01$ ), and indicates that big data investments $(\beta=59, p<.01)$, big data availability $(\beta=.47, p<.01)$, the $\mathrm{B} 2 \mathrm{~B}$ vs. $\mathrm{B} 2 \mathrm{C}$ focus $(\beta=1.82, p<.01)$, and service mix $(\beta=$ $-1.30, p<.05$ ) are significantly linked with $\mathrm{T}_{2}$ data availability. We included the correction term IMR in the final model estimation. To identify second-stage parameters, in line with recommended exclusion restrictions (Hausman 1978), we dropped the B2B vs. B2C focus and service mix variables from our final models, as they satisfy both relevance and exogeneity requirements (i.e., they do not have direct relationships with the dependent variables - all $r<.08$, all $p>.38$ - but explain firms' choice to participate in the second survey).

Next, we estimated the LIV corrections for each independent variable (Wang et al. 2017). The Akaike Information Criterion (AIC3) suggested three-support point solutions for big data investments and customer behavior pattern spotting, and four-support point solutions for real-time market responsiveness, data-driven market ambidexterity, and service innovation. ${ }^{13}$

Finally, we estimated Eqs. 4a to $4 \mathrm{e}$ simultaneously. We standardized all explanatory variables, used robust standard errors, and excluded non-significant controls from the equations to have the most parsimonious model. In particular, number of data specialists, firm size, and firm age were excluded from our model. The variance inflation factors ruled

\footnotetext{
$\overline{13}$ The AIC3 values for one through five support points, respectively, were as follows: big data investments $=178.38,176.55,169.40,179.57,182.34$; customer behavior pattern spotting $=209.07,210.15,208.35,216.16,228.53$; data-driven market ambidexterity $=222.17,221.44,223.70,219.42,220.80$; real-time decision making $=237.41,233.42,233.84,230.46,234.26$; and service innovation $=159.96,155.42,155.00,154.81,157.13$.
}

out any multicollinearity concerns (all VIF <2.65). The AIC3 criterion for the final model suggested a two-support point solution to control for unobserved heterogeneity. ${ }^{14}$

Hypothesis testing We present the results from three models in Table 5, one model without endogeneity correction, the hypothesized model, and a model with an additional, nonsignificant, interaction effect of industry digitalization and customer behavior pattern spotting on perceived big data performance. Although the results are generally consistent across models, some LIV error terms and the IMR suggest the importance of accounting for endogeneity. Thus, we discuss the results of the hypothesized model that incorporates the endogeneity correction (Model 2).

The results offer support for the positive effects of big data investments on customer behavior pattern spotting $(\gamma=.34$, $p<.01)$, real-time market responsiveness $(\gamma=.37, p<.01)$, and data-driven market ambidexterity $(\gamma=.46, p<.01)$, in support of H1a, H1b, and H1c.

Real-time market responsiveness $(\gamma=.24, p<.05)$, and data-driven market ambidexterity $(\gamma=.30, p<.01)$, but not customer behavior pattern spotting $(\gamma=-.14, n s)$, are positively related to service innovation. Consequently, both realtime market responsiveness (indirect effect: $\gamma=.09,95 \%$ $\mathrm{CI}=.01$ to .17 ), and data-driven market ambidexterity (indirect effect: $\gamma=.14,95 \% \mathrm{CI}=.04$ to .24 ), mediate the relationship between big data investments and service innovation. Thus, $\mathrm{H} 2 \mathrm{~b}$ and $\mathrm{H} 2 \mathrm{c}$ are supported, while H2a is not (Table 6).

Service innovation has a positive effect on perceived big data performance $(\gamma=.26, p<.01)$, and mediates the effects of real-time market responsiveness (indirect effect: $\gamma=.06$, $95 \% \mathrm{CI}=.01$ to .11 ), and data-driven market ambidexterity (indirect effect: $\gamma=.08,95 \% \mathrm{CI}=.01$ to .14 ) on perceived big data performance, supporting $\mathrm{H} 3 \mathrm{~b}$ and $\mathrm{H} 3 \mathrm{c}$. Customer behavior pattern spotting has a positive direct effect on perceived big data performance $(\gamma=.26, p<.01)$, rejecting H3a.

We also find an indirect effect of big data investments on perceived big data performance via customer behavior pattern spotting (single mediation: $\gamma=.09,95 \% \mathrm{CI}=.03$ to .15 ), and an indirect effect of big data investments on perceived big data performance via real-time market responsiveness/data-driven market ambidexterity, and service innovation (serial mediation: $\gamma=.06,95 \% \mathrm{CI}=.02$ to .10 ), in support of $\mathrm{H} 4 \mathrm{a}$ and partial support of $\mathrm{H} 4 \mathrm{~b} .^{15}$

We further find a positive and significant interaction effect between service innovation and industry digitalization on perceived big data performance $(\gamma=.25, p<.01)$, in support of

\footnotetext{
$\overline{14}$ The AIC3 values were as follows: $350.04,341.31,342.76,345.22,351.67$.

${ }^{15}$ Switching the order of the mediators, the indirect effect of big data investments on perceived big data performance becomes non-significant (big data investments $\rightarrow$ service innovation $\rightarrow$ customer behavior pattern spotting, realtime market responsiveness, and data-drive market ambidexterity $\rightarrow$ perceived big data performance; $\gamma=.00, p=.80,95 \% \mathrm{CI}=-.03, .04)$.
} 
Table 5 Results of Study 2

Model 1: Main effects Model 2: Hypothesized model Model 3: Additional interaction

DV: Customer Behavior Pattern Spotting

Big data investments

Big data availability

Data oriented culture

Big data investments (error term)

IMR

$R^{2}$ Customer Behavior Pattern Spotting

DV: Real-Time Market Responsiveness

Big data investments

Big data availability

Data oriented culture

Big data investments (error term)

IMR

$R^{2}$ Real-Time Market Responsiveness

DV: Data-Driven Market Ambidexterity

Big data investments

Big data availability

Data oriented culture

Big data investments (error term)

IMR

$R^{2}$ Data-Driven Market Ambidexterity

$D V$ : Service Innovation

Customer behavior pattern spotting

Real-time market responsiveness

Data-driven market ambidexterity

Big data investments

Customer behavior pattern spotting (error term)

Real-time market responsiveness (error term)

Data-driven market ambidexterity (error term)

Big data investments (error term)

IMR

$R^{2}$ Service Innovation

DV: Perceived Big Data Performance

Service innovation

Customer behavior pattern spotting

Real-time market responsiveness

Data-driven market ambidexterity

Big data investments

Data oriented culture

Marketing-IT collaboration

Digitalization of industry (DI)

Service innovation (error term)

Customer behavior pattern spotting (error term)

Real-time market responsiveness (error term)

Data-driven market ambidexterity (error term)

Big data investments (error term)

Support Point 1

Support Point 2

IMR

\begin{tabular}{|c|c|c|c|c|c|}
\hline .440 & $(.101)^{* * *}$ & .336 & $(.099) * * *$ & .336 & $(.099) * * *$ \\
\hline .265 & $(.082)^{* * * *}$ & .278 & $(.089) * * *$ & .278 & $(.089) * * *$ \\
\hline \multirow[t]{3}{*}{.063} & $(.116)$ & .097 & $(.112)$ & .097 & $(.112)$ \\
\hline & & .155 & $(.078)^{*}$ & .155 & $(.078)^{*}$ \\
\hline & & .090 & $(.080)$ & .090 & $(.080)$ \\
\hline .394 & & .362 & & .362 & \\
\hline .310 & $(.117)^{* * * *}$ & .371 & $(.111)^{* * *}$ & .371 & $(.111)^{* * * *}$ \\
\hline .157 & $(.113)$ & .215 & $(.101)^{* *}$ & .215 & $(.101)^{* *}$ \\
\hline \multirow[t]{3}{*}{.216} & $(.119)^{*}$ & .233 & $(.103)^{* *}$ & .233 & $(.103)^{* *}$ \\
\hline & & .068 & $(.088)$ & .068 & $(.088)$ \\
\hline & & .165 & $(.084)^{* *}$ & .165 & $(.084)^{* *}$ \\
\hline .294 & & .389 & & .389 & \\
\hline .358 & $(.130)^{* * * *}$ & .459 & $(.112)^{* * *}$ & .459 & $(.112)^{* * *}$ \\
\hline .044 & $(.136)$ & .012 & $(.120)$ & .012 & $(.120)$ \\
\hline \multirow[t]{3}{*}{.165} & $(.114)$ & .190 & $(.105)^{*}$ & .190 & $(.105)^{*}$ \\
\hline & & .154 & $(.087)^{*}$ & .154 & $(.087)^{*}$ \\
\hline & & .309 & $(.075)^{* * *}$ & .309 & $(.075)^{* * *}$ \\
\hline .222 & & .314 & & .314 & \\
\hline-.085 & $(.105)$ & -.138 & $(.110)$ & -.138 & $(.110)$ \\
\hline .208 & $(.102)^{* *}$ & .237 & $(.190)^{* *}$ & .237 & $(.119)^{* *}$ \\
\hline .357 & $(.121)^{* * * *}$ & .295 & $(.117)^{* * *}$ & .295 & $(.117)^{* * * *}$ \\
\hline \multirow[t]{6}{*}{.158} & $(.103)$ & .117 & $(.112)$ & .117 & $(.112)$ \\
\hline & & -.036 & $(.091)$ & -.036 & $(.091)$ \\
\hline & & .022 & $(.092)$ & .022 & $(.092)$ \\
\hline & & .015 & $(.089)$ & .015 & $(.089)$ \\
\hline & & -.014 & $(.091)$ & -.014 & $(.091)$ \\
\hline & & .061 & $(.127)$ & .061 & $(.127)$ \\
\hline .284 & & .271 & & .271 & \\
\hline .312 & $(.110)^{* * * *}$ & .256 & $(.081) * * *$ & .245 & $(.081)^{* * * *}$ \\
\hline .313 & $(.095) * * *$ & .262 & $(.079) * * *$ & .268 & $(.076)^{* * *}$ \\
\hline .027 & $(.089)$ & .059 & $(.096)$ & .026 & $(.095)$ \\
\hline .058 & (.119) & .111 & $(.114)$ & .149 & (.119) \\
\hline-.101 & $(.100)$ & -.123 & $(.107)$ & -.117 & (.109) \\
\hline .149 & $(.090)^{*}$ & .109 & $(.097)$ & .096 & $(.096)$ \\
\hline .035 & $(.080)$ & .165 & $(.091)^{*}$ & .193 & $(.089)^{* *}$ \\
\hline \multirow[t]{9}{*}{-.111} & $(.071)$ & -.082 & $(.070)$ & -.087 & $(.070)$ \\
\hline & & -.011 & $(.084)$ & -.003 & $(.086)$ \\
\hline & & .057 & $(.076)$ & .048 & $(.076)$ \\
\hline & & -.026 & $(.067)$ & -.031 & $(.070)$ \\
\hline & & .033 & $(.075)$ & .029 & $(.075)$ \\
\hline & & -.072 & $(.078)$ & -.090 & $(.077)$ \\
\hline & & .452 & $(.052) * * *$ & .441 & $(.052) * * *$ \\
\hline & & -.057 & $(.065)$ & -.057 & $(.065)$ \\
\hline & & -.234 & $(.098)^{* *}$ & -.242 & $(.099) * *$ \\
\hline
\end{tabular}


Table 5 (continued)

\begin{tabular}{|c|c|c|c|c|c|c|}
\hline \multirow[b]{2}{*}{$\mathrm{DI} \times$ Service innovation } & \multicolumn{2}{|c|}{ Model 1: Main effects } & \multicolumn{2}{|c|}{ Model 2: Hypothesized model } & \multicolumn{2}{|c|}{ Model 3: Additional interaction } \\
\hline & .198 & $(.089)^{* *}$ & .245 & $(.079)^{* * *}$ & .226 & $(.076)^{* * *}$ \\
\hline DI $\times$ Service innovation (error term) & & & -.095 & $(.074)$ & -.120 & $(.079)$ \\
\hline DI $\times$ Customer behavior pattern spotting & & & & & .016 & $(.075)$ \\
\hline $\mathrm{DI} \times$ Customer behavior pattern spotting (error term) & & & & & .113 & $(.066)$ \\
\hline$R^{2}$ Perceived Big Data Performance & .375 & & .481 & & .495 & \\
\hline Akaike Information Criteria & 1407.59 & & 1415.46 & & 1416.75 & \\
\hline Bayesian Information Criteria & 1392.88 & & 1391.57 & & 1391.94 & \\
\hline
\end{tabular}

Notes: $* * * p<.01, * * p<.05, * p<.10$. Significance is based on two-tailed tests, standard errors in parentheses

H5a. Service innovation is positively related to perceived big data performance in industries with high digitalization $(\gamma=.51, p<.01)$, but not in industries with low digitalization $(\gamma=.01, n s)$.

The indirect effect of big data investments on perceived big data performance via the serial mediation of real-time market responsiveness/data-driven market ambidexterity and service innovation is also contingent on industry digitalization. Big data investments are positively linked to perceived big data performance in industries with high digitalization $(\gamma=.22$, $95 \% \mathrm{CI}=.07$ to .36 ), but not in industries with low digitalization $(\gamma=-.02,95 \% \mathrm{CI}=-.07$ to .04$)$. Thus, H5b is supported.
Given the direct effect of customer behavior pattern spotting on perceived big data performance, we explored whether industry digitalization also moderates this effect in Model 3 but did not find a significant interaction $(\gamma=.02, n s)$. Thus, even firms in low-digitalization industries may benefit from big data investments via customer behavior pattern spotting $(\gamma=.09,95 \% \mathrm{CI}=.01$ to .16$)$.

Robustness tests Since we measured both service innovation and perceived big data performance at $\mathrm{T}_{2}$, we collected additional performance data to test for a lagged effect of service innovation. We were able to obtain data from a subsample of

Table 6 Indirect effects in Study 2

\begin{tabular}{|c|c|}
\hline Hypothesis & Indirect effect \\
\hline \multicolumn{2}{|l|}{ Mediation of Big Data Marketing Affordances (H2) } \\
\hline $\begin{array}{l}\text { H2a: Big data investments } \rightarrow \text { customer behavior pattern } \\
\text { spotting } \rightarrow \text { service innovation }\end{array}$ & $-.046(95 \% \mathrm{CI}=-.109$ to .016$)$ \\
\hline $\begin{array}{l}\mathrm{H} 2 \mathrm{~b}: \text { Big data investments } \rightarrow \text { real-time market } \\
\text { responsiveness } \rightarrow \text { service innovation }\end{array}$ & $.088(95 \% \mathrm{CI}=.005$ to .171$)$ \\
\hline $\begin{array}{l}\text { H2c: Big data investments } \rightarrow \text { data-driven market } \\
\text { ambidexterity } \rightarrow \text { service innovation }\end{array}$ & $.136(95 \% \mathrm{CI}=.035$ to .236$)$ \\
\hline \multicolumn{2}{|l|}{ Mediation of Service Innovation (H3) } \\
\hline $\begin{array}{l}\text { H3a: Customer behavior pattern spotting } \rightarrow \text { service } \\
\text { innovation } \rightarrow \text { perceived big data performance }\end{array}$ & $-.035(95 \% \mathrm{CI}=-.083$ to .013$)$ \\
\hline $\begin{array}{l}\text { H3b: Real-time market responsiveness } \rightarrow \text { service } \\
\text { innovation } \rightarrow \text { perceived big data performance }\end{array}$ & $.061(95 \% \mathrm{CI}=.010$ to .111$)$ \\
\hline $\begin{array}{l}\text { H3c: Data-driven market ambidexterity } \rightarrow \text { service } \\
\text { innovation } \rightarrow \text { perceived big data performance }\end{array}$ & $.075(95 \% \mathrm{CI}=.012$ to .139$)$ \\
\hline \multicolumn{2}{|c|}{ Serial Mediation of Big Data Marketing Affordances (H4a) and Service Innovation (H4b) } \\
\hline $\begin{array}{l}\text { Big data investments } \rightarrow \text { customer behavior pattern } \\
\text { spotting } \rightarrow \text { perceived big data performance }\end{array}$ & $.088(95 \% \mathrm{CI}=.028$ to .149$)$ \\
\hline $\begin{array}{l}\text { Big data investments } \rightarrow \text { real-time market responsiveness } \\
\text { and data-driven market ambidexterity } \rightarrow \text { service } \\
\text { innovation } \rightarrow \text { perceived big data performance }\end{array}$ & $.057(95 \% \mathrm{CI}=.015$ to .099$)$ \\
\hline \multicolumn{2}{|l|}{ Conditional Indirect Effect of Big Data Investments (H5b) } \\
\hline $\begin{array}{l}\text { Indirect effect of big data investments on perceived big } \\
\text { data performance with low digitalization of the } \\
\text { industry }\end{array}$ & $-.016(95 \% \mathrm{CI}=-.071$ to .039$)$ \\
\hline $\begin{array}{l}\text { Indirect effect of big data investments on perceived big } \\
\text { data performance with high digitalization of the } \\
\text { industry }\end{array}$ & $.216(95 \% \mathrm{CI}=.074$ to .357$)$ \\
\hline
\end{tabular}


51 participants two years after the initial data collection ( $46 \%$ response rate). The time-lagged perceived big data performance measure has a strong positive correlation with perceived big data performance in the original data collection $(r=.56)$, and results of a simple regression analysis are in line with our main analysis: service innovation has a positive effect on lagged perceived big data performance $(\gamma=.27, p<.01)$, and this effect is moderated by industry digitalization $(\gamma=.27$, $p<.05)$.

Results from Study 2 provide a further validation of the three scales and generally support our expectations regarding the chain of relationships connecting big data investments to perceived big data performance, via big data marketing affordances and service innovation. We show that service innovation mediates between real-time market responsiveness and data-driven market ambidexterity and perceived big data performance; in contrast, customer behavior pattern spotting is directly related to perceived big data performance. We also find an overall indirect positive effect of big data investments on perceived big data performance, indicating that investing resources into big data may drive superior performance. Yet, this indirect effect is conditional on industry digitalization, as firms in highly digitalized industries benefit more from big data investments. Still, all firms benefit from customer behavior pattern spotting.

\section{Discussion}

\section{Theoretical implications}

Our study provides several important contributions to theory. First, we introduce affordance theory to the marketing strategy literature. Information technologies generate possibilities for marketing actions that reshape the competitive landscape. This implies a transformation of marketing towards the formerly specialized area of service marketing and an increased emphasis on marketing analytics (Rust and Huang 2014). To address this challenge, the marketing theory toolkit needs to be enriched with new concepts, logics, and relationships that account for the digitized world. This purpose is well served by affordance theory, which is emerging as the overarching theoretical framework to understand the impact of technological developments for organizations (Nambisan et al. 2017). Our newly developed measures of big data marketing affordances represent a step forward in big data marketing research, and allow for the first quantitative test of affordance theory in the literature. In addition, by widening the scope of big data affordances to the marketing domain, we address a limitation of previous studies of big data affordances that focused predominantly on technological affordances (Dremel et al. 2020; Lehrer et al.
2018). In fact, while our big data marketing affordances scales are anchored to BDTA, their conceptualization and nomological implications go beyond data management and analytics. Thus, our conceptualization and empirical findings connect recent theoretical developments from marketing and IS, and answer calls for a more solid platform of interdisciplinary research between these two fields (Rust and Huang 2014).

Second, we contribute to the literature on marketing analytics and service innovation in data-rich environments (e.g., Troilo et al. 2017; Wedel and Kannan 2016) by identifying different antecedents of service innovation among big data marketing affordances. We find that while real-time market responsiveness and data-driven ambidexterity lead to service innovation, customer behavior pattern spotting does not. This result deviates from our prediction and is worth attention. A possible explanation is that customer behavior pattern spotting is deployed in an exploitation mode, to optimize existing service processes and performance. This may be plausible especially if managers look for patterns of customer behaviors in well-known domains that are linked to short-term marketing metrics, such as for example reducing churn, increasing customer engagement, or improving communication campaigns. All these outcomes will benefit significantly from customer behavior pattern spotting but may produce rather negligible effects on service innovation. Conceptually, this implies different routes through which the effect of big data investments generates superior performance. Big data marketing affordances relate to perceived big data performance either via service innovation (for real-time market responsiveness and data-driven market ambidexterity), or directly (for customer behavior pattern spotting); thus, we provide a more nuanced picture the contribution of big data investments and marketing affordances to perceived big data performance compared to previous literature.

Third, our middle-range theorizing approach fills an important gap between general and more de-contextualized theories of the link between big data investments and performance, prevalent in IS and strategic management (resource-based view, knowledge-based view, and dynamic capabilities; e.g., Wamba et al. 2017; Grover et al. 2018), and the need for a tighter connection between theoretical formulation and empirical findings in the marketing context (Brodie et al. 2011). In fact, the mechanisms through which BDTA operate are radically different from the traditionally known sources of market intelligence, as big data emerge unintentionally, are mostly unstructured, and often redundant. Thus, the meaning and value of big data is defined 'on the way out' rather than 'on the way in' (Constantiou and Kallinikos 2015). Our affordance theory framework addresses this issue by promoting an action- 
based view of the value of BDTA for marketing, against previous explanations based on organizational information processing (Maltz and Kohli 1996), and the knowledgebased view (Erevelles et al. 2016).

Finally, to further strengthen this point, we also find that big data investments pay off more in highly digitalized industries, owing to the moderating role of industry digitalization between service innovation and perceived big data performance; this finding extends previous marketing literature that narrowly focused on the direct effects of big data investments on the bottom-line (e.g., Wamba et al. 2017). This additional result contributes to the emerging literature describing the process, and conditions under which, big data investments and digital transformation efforts pay off for companies (Müller et al. 2018).

\section{Managerial implications}

Managers aiming to exploit the potential of BDTA find limited inspiration from extant research rooted in traditional marketing paradigms. Through our affordance theory lens, we offer marketing decision-makers some recommendations to reap the benefits of big data investments.

Shift your efforts from data to actions Managers must be aware that what makes big data pay off is not their large volume, high velocity, or broad variety but rather the organizational ability to actualize the action potential offered by BDTA (Shah et al. 2012). We introduce three big data marketing affordances that may guide the extraction of valuable marketing insights from data and the implementation of corresponding actions. In fact, customer behavior pattern spotting allows organizations to increase the effectiveness and efficiency of marketing activities; real-time market responsiveness affords the ability to respond to market events with minimal time latency; datadriven market ambidexterity improves a firm's ability to identify new market opportunities leveraging on their current offers. For this reason, managers must identify those actors within their organization who are in the best position to actualize BTDA marketing affordances, and empower them with the responsibility to take actions.

Anticipate your return on investment pathway Our findings show that these three affordances provide two alternative routes to performance. The first route leads to the improvement of the efficiency and effectiveness of actual marketing activities. Managers who wish to follow this path should invest in BDTA that afford the identification of patterns of customer behaviors, thereby allowing organizational members to optimize budget allocations across marketing activities. The second route aims to innovate in terms of new service concepts, processes, or customer experience. Managers who are prone to achieve this objective should focus their efforts on BDTA that afford the implementation of individualized marketing actions nurtured by data collected in real time, and on BDTA that identify market opportunities built on the synergies between new and existing service offers.

Sync your big data strategy with your industry digitalization stage Our findings point to the contingent effect of industry digitalization. In fact, if an industry is at an earlier stage of digitalization, managers should focus on improving efficiency and effectiveness via customer behavior pattern spotting. Managers competing in industries at a later stage of digitalization should complement such affordance with data-driven service innovations that build on increased marketing action potential allowed by real time market responsiveness and the creation of new opportunities allowed by data-driven market ambidexterity.

Expect the unexpected insight Big data investments change the way to acquire, disseminate, and use market intelligence. In fact, big data investments enable to complement structured data intentionally collected through more traditional marketing research activities for premeditated information needs with a large variety of unstructured data. To benefit from such opportunities, managers must design and implement actions to leverage on emerging and unexpected patterns of customer behaviors, to allocate decision-making responsibilities to exploit real-time responsiveness to unexpected market events, and to favor new opportunities stemming from the synergies between existing and future services.

Adopt a servitization perspective in every industry Due to digitization and the availability of BDTA, the boundaries between services industry and the goods sector are blurring. For example, the Internet-of-Things enables product-driven manufacturing firms to collect big data on customer behaviors and leverage these data to design innovative services. Although we focus on service innovation, we believe that our implications generalize beyond the service industry. Thus, we also recommend managers in manufacturing firms to adopt a service-based perspective in order to reap the benefit of BDTA.

\section{Limitations and future research directions}

Our study offers theoretical, empirical, and managerial contributions as highlighted in the previous sections, yet it is also subject to some limitations that need to be acknowledged. First, we collected self-reported and some close-to-factual data, yet we were not able to employ secondary data to measure variables such as big data 
investments or big data performance. Future research may use multi-source data to further corroborate our findings. In particular, it would be desirable to disentangle the dimensions of big data performance in future studies. Second, our samples of informants come from two European countries (Italy and Switzerland), with relatively similar business environments, broadly comparable to those of developed Western countries. Thus, our findings do not immediately generalize to other geographical settings with different business contexts around big data investments and use (i.e., China). Third, we only consider three types of big data marketing affordances based on previous conceptual literature; while we provide empirical evidence of their relevance and significance for managers, future research should consider new and emerging affordances and their antecedents and consequences, in order to capture their dynamic nature across actor/time/space combinations. For example, our data point to sales-related affordances as an attractive area for future research.

In addition to addressing the limitations highlighted above, future research could unearth the organizational processes through which firms actualize big data marketing affordances. This could be done by including a set of contingencies in the relationship between big data investments and big data marketing affordances, and between the latter and service innovation. Another avenue for future research based on our frame- work is to analyze big data investments and affordances at the individual level (i.e., frontline employee, salesperson) or the team level (i.e., service or sales teams) to complement our organizational-level approach (Marinova et al. 2017). This effort will be consistent with the multi-level nature of customer service, affordances, and innovation already highlighted in the respective literatures. Finally, while we focus on the firm's perspective, future work can look at the possibilities for action that BDTA offer to individual customers, and how these affect customers' behavior, engagement, and other relevant marketing outcomes. To conclude, our study can inspire researchers and doctoral students from marketing and IS to develop a joint platform for theoretical and empirical research. We show how marketing researchers may adopt affordance theory as a theoretical lens to investigate BDTA, artificial intelligence and other related technologies in relation to marketing strategy outcomes; in parallel, we offer IS researchers the opportunity to incorporate our constructs and measures in future quantitative studies of big data affordances in organizations.

Acknowledgments The Authors have presented the paper to the 2019 JAMS Thought Leaders Conference connected to the Special Issue, and acknowledge the insightful comments and feedback from John Hulland and other participants. We are also indebted with all the managers who have engaged with our research, many of whom have also provided feedback on our results.

\section{Appendix}

Table 7 Constructs and measurement items

\begin{tabular}{lc}
\hline & Item reliabilities \\
\cline { 2 - 2 } Variables and items & Study $1 \mathrm{c}$ \\
\hline Customer Behavior Pattern Spotting & $\alpha=.95$ \\
Big data technologies and analytics afford our company to: & Study 2 \\
-Identify patterns of customer behavior across our touchpoints & .80 \\
-Predict undesirable customer behaviors, such as for example complaints or churn & .83 \\
-Predict desirable customer behaviors, such as for example propensity to buy or word-of-mouth & .82 \\
-Identify patterns of competitive actions affecting our customers & .90 \\
Real-Time Market Responsiveness & $\alpha=.94$ \\
Big data technologies and analytics afford our company to: & .86 \\
-Perform real-time analyses & .77 \\
-Make real-time decisions & .90 \\
-Implement real-time decision rules & .84 \\
-Identify the best next action in customer interactions & .68 \\
Data-Driven Market Ambidexterity & $\alpha=.90$ \\
Big data technologies and analytics afford our company to: & .72 \\
-Explore synergies with our current offerings & .73 \\
-Identify new strategic opportunities & .52 \\
-Visualize the connection between our current products/services and future ones & $\alpha=.96$ \\
-Identify synergies between our current and future customer needs & .83 \\
Big Data Availability (based on Johnson et al. 2017) & .76 \\
-We increasingly collect and analyze data in real-time & .75 \\
-We collect data from an increasing variety of sources & .74 \\
- The amount of data we collect is growing continuously & $\alpha=.85$
\end{tabular}


Table 7 (continued)

Item reliabilities

Variables and items

Study 1c

$\begin{array}{ll}\alpha=.95 & \alpha=.90 \\ .72 & .50 \\ .79 & .49 \\ & \\ .66 & .48 \\ .72 & .59 \\ .83 & .71 \\ .74 & .72 \\ .83 & .62 \\ \alpha=.91 & \alpha=.89\end{array}$

Data Oriented Culture (based on Davenport et al. 2012)

-Our entire organization values data-based analysis and decision-making

-In our firm, people believe that predictions and decisions should be supported by solid

data analysis, rather than intuition and personal feelings

-In our firm, everyone understands the importance of data

-Our senior managers encourage the use of data in every area of the business

-Data-driven decision-making permeates our firm at all levels

-Data analytics are used across the firm, and not only by a small number of data experts

-Data-driven decision-making is the norm in our firm

Marketing-IT Collaboration (Kahn and Mentzer 1998)

Marketing and IT departments in my firm:

-Have a mutual understanding

-Informally work together

-Share ideas and information

-Work together as a team

Big Data Investments (based on McAfee et al. 2012; Wamba et al. 2017)

-Relative to our budget, we have invested a lot in big data projects

-Big data are a priority when it comes to resource allocation

-We hired a lot of new people to work with big data

Service Innovation (Barrett et al. 2015; Den Hertog 2000)

-Service concept innovation

-Service process innovation

- Customer experience innovation

Service concept innovation

-Ability to develop new service offerings

-Launching new solutions to customer needs or problems

-Recombining elements of existing services in new configurations

Service process innovation

-Developing new or enhanced internal service delivery systems

-Implementing new processes and systems that allow service employees to serve customers more

efficiently and effectively

-Finding new ways to optimize service process efficiency

Customer experience innovation

-Innovation in the customer touch-points involved in the service delivery

-Creatively change the number and quality of the customer touch-points to match the customer context

.72

$$
.58
$$$$
.81
$$

.76

-Creating a new customer experience

Perceived Big Data Performance (Wamba et al. 2017)

-Big data are an overall success

-Big data success exceeds expectations

-Big data add substantial value to our products and services

-Big data was a good idea to invest in

Notes: The data collection took place in Italian for Study 1c and in German for Study 2. We the measurement for the full sample of Study 2

Open Access This article is licensed under a Creative Commons Attribution 4.0 International License, which permits use, sharing, adaptation, distribution and reproduction in any medium or format, as long as you give appropriate credit to the original author(s) and the source, provide a link to the Creative Commons licence, and indicate if changes were made. The images or other third party material in this article are included in the article's Creative Commons licence, unless indicated otherwise in a credit line to the material. If material is not included in the article's Creative Commons licence and your intended use is not permitted by statutory regulation or exceeds the permitted use, you will need to obtain permission directly from the copyright holder. To view a copy of this licence, visit http://creativecommons.org/licenses/by/4.0/.

\section{References}

Balducci, B., \& Marinova, D. (2018). Unstructured data in marketing. Journal of the Academy of Marketing Science, 46(1), 557-590.

Barrett, M., Davidson, E., Prabhu, J., \& Vargo, S. L. (2015). Service innovation in the digital age: Key contributions and future directions. MIS Quarterly, 39(1), 135-154.

Bean, R., \& Davenport, T, H. (2019). Companies are failing in their efforts to become data driven. Harvard Business Review. https:// hbr.org/2019/02/companies-are-failing-in- their-efforts-to-becomedata-driven. 
Brinker, S., \& McLellan, L. (2014). The rise of the chief marketing technologist. Harvard Business Review, 92(7), 82-85.

Brodie, R. J., Saren, M., \& Pels, J. (2011). Theorizing about the service dominant logic: The bridging role of middle range theory. Marketing Theory, 11(1), 75-91.

Chemero, A. (2003). An outline of a theory of affordances. Ecological Psychology, 15(2), 181-195.

Chen, H., Chiang, R. H. L., \& Storey, V. C. (2012). Business intelligence and analytics: From big data to big impact. MIS Quarterly, 36(4), $1165-1188$

Churchill Jr., G. A. (1979). A paradigm for developing better measures of marketing constructs. Journal of Marketing Research, 16(1), 64-73.

Constantiou, I. D., \& Kallinikos, J. (2015). New games, new rules: Big data and the changing context of strategy. Journal of Information Technology, 30(1), 44-57.

Davenport, T, H., \& Bean, R. (2019). Big data and AI executive survey. New Vantage Partners (NVP), Technical Report.

Davenport, T. H., Barth, P., \& Bean, R. (2012). How 'big data' is different. MIT Sloan Management Review, 54(1), 22-24.

Den Hertog, P. (2000). Knowledge-intensive business services as coproducers of innovation. International Journal of Innovation Management, 4(4), 491-528.

Dotzel, T., Shankar, V., \& Berry, L. L. (2013). Service innovativeness and firm value. Journal of Marketing Research, 50(2), 259-276.

Dremel, C., Herterich, M. M., Wulf, J., \& vom Brocke, J. (2020). Actualizing big data analytics affordances: A revelatory case study. Information \& Management, 57(1), 1-21.

Ebbes, P., Wedel, M., Böckenholt, U., \& Steerneman, T. (2005). Solving and testing for regressor-error (in) dependence when no instrumental variables are available: With new evidence for the effect of education on income. Quantitative Marketing and Economics, 3(4), 365 392.

Edeling, A., \& Himme, A. (2018). When does market share matter? New empirical generalizations from a meta-analysis of the market shareperformance relationship. Journal of Marketing, 82(3), 1-24.

Erevelles, S., Fukawa, N., \& Swayne, L. (2016). Big data consumer analytics and the transformation of marketing. Journal of Business Research, 69(2), 897-904.

Gandhi, P., Khanna, S., \& Ramaswamy, S. (2016). Which industries are the most digital (and why)? Harvard Business Review [available at https://hbr.org/2016/04/a-chart-that-shows-which-industries-arethe-most-digital-and-why].

Gandomi, A., \& Haider, M. (2015). Beyond the hype: Big data concepts, methods, and analytics. International Journal of Information Management, 35(2), 137-144.

Gerbing, D. W., \& Anderson, J. C. (1988). An updated paradigm for scale development incorporating unidimensionality and its assessment. Journal of Marketing Research, 25(2), 186-192.

Germann, F., Lilien, G. L., Fiedler, L., \& Kraus, M. (2014). Do retailers benefit from deploying customer analytics? Journal of Retailing, 90(4), 587-593.

Gibson, J. J. (1979). The ecological approach to visual perception. Boston: Houghton Mifflin.

Gielens, K., \& Steenkamp, J. B. E. (2007). Drivers of consumer acceptance of new packaged goods: An investigation across products and countries. International Journal of Research in Marketing, 24(2), 97-111.

Grover, V., Roger, H. L. C., Ting-Peng, L., \& Dongsong, Z. (2018). Creating strategic business value from big data analytics: A research framework. Journal of Management Information System, 35(2), $388-423$.

Han, J. K., Kim, N., \& Srivastava, R. K. (1998). Market orientation and organizational performance: Is innovation a missing link? Journal of Marketing, 62(4), 30-45.

Hausman, J. (1978). Specification tests for econometrics. Econometrica, $46,1251-1271$.
Herhausen, D., Emrich, O., Grewal, D., Kipfelsberger, P., \& Schoegel, M. (2020). Face forward: How employees' digital presence on service websites affects customer perceptions of website and employee service quality. Journal of Marketing Research, forthcoming., 002224372093486

Homburg, C., Schwemmle, M., \& Kuehnl, C. (2015). New product design: Concept, measurement, and consequences. Journal of Marketing, 79(3), 41-56.

Huang, M. H., \& Rust, R. T. (2017). Technology-driven service strategy. Journal of the Academy of Marketing Science, 45(6), 906-924.

Hulland, J., Baumgartner, H., \& Smith, K. M. (2018). Marketing survey research best practices: Evidence and recommendations from a review of JAMS articles. Journal of the Academy of Marketing Science, 46(1), 92-108.

Hutchby, I. (2001). Technologies, texts, and affordances. Sociology, $35(2), 441-456$.

Johnson, J. S., Friend, S. B., \& Lee, H. S. (2017). Big data facilitation, utilization, and monetization: Exploring the $3 \mathrm{Vs}$ in a new product development process. Journal of Product Innovation Management, 34(5), 640-658.

Kahn, K. B., \& Mentzer, J. T. (1998). Marketing's integration with other departments. Journal of Business Research, 42(1), 53-62.

Kuehnl, C., Jozic, D., \& Homburg, C. (2019). Effective customer journey design: Consumers' conception, measurement, and consequences. Journal of the Academy of Marketing Science, 47(3), 551-568.

Kumar, N., Stern, L. W., \& Anderson, J. C. (1993). Conducting interorganizational research using key informants. Academy of Management Journal, 36(6), 1633-1651.

Kumar, V., Chattaraman, V., Neghina, C., Skiera, B., Aksoy, L., Buoye, A., \& Henseler, J. (2013). Data-driven services marketing in a connected world. Journal of Service Management, 24(3), 330-352.

Lambrecht, A., \& Tucker, C, E. (2015). Can big data protect a firm from competition? Working paper, available at SSRN 2705530.

Laney, D. (2001). 3D data management: Controlling data volume, velocity, and variety. META Group Research Note, 6(70), 70-73.

Lehrer, C., Wieneke, A., vom Brocke, J., Jung, R., \& Seidel, S. (2018). How big data analytics enables service innovation: Materiality, affordance, and the individualization of service. Journal of Management Information Systems, 35(2), 424-460.

Lycett, M. (2013). 'Datafication': Making sense of (big) data in a complex world. European Journal of Information Systems, 22(4), 381386.

Majchrzak, A., \& Markus, M. L. (2013). Technology affordances and constraints in management information systems (MIS). In E. H. Kessler (Ed.), Encyclopedia of management theory. Sage Publications.

Maltz, E., \& Kohli, A. K. (1996). Market intelligence dissemination across functional boundaries. Journal of Marketing Research, 33(1), 47-61.

March, J. G. (1991). Exploration and exploitation in organizational learning. Organization Science, 2(1), 71-87.

Marinova, D., de Ruyter, K., Huang, M. H., Meuter, M. L., \& Challagalla, G. (2017). Getting smart: Learning from technologyempowered frontline interactions. Journal of Service Research, 20(1), 29-42.

Marketing Science Institute. (2018). Research priorities 2018-2020. Cambridge, Mass: Marketing Science Institute.

McAfee, A., Brynjolfsson, E., Davenport, T. H., Patil, D. J., \& Barton, D. (2012). Big data: The management revolution. Harvard Business Review, 90(10), 60-68.

Mikalef, P., Boura, M., Lekakos, G., \& Krogstie, J. (2019). Big data analytics capabilities and innovation: The mediating role of dynamic capabilities and moderating effect of the environment. British Journal of Management, 30(2), 272-298.

Miles, I. (2008). Patterns of innovation in service industries. IBM Systems Journal, 47(1), 115-128. 
Mizik, N., \& Jacobson, R. (2003). Trading off between value creation and value appropriation: The financial implications of shifts in strategic emphasis. Journal of Marketing, 67(1), 63-76.

Müller, O., Fay, M., \& vom Brocke, J. (2018). The effect of big data and analytics on firm performance: An econometric analysis considering industry characteristics. Journal of Management Information Systems, 35(2), 488-509.

Nambisan, S., Lyytinen, K., Majchrzak, A., \& Song, M. (2017). Digital innovation management: Reinventing innovation management research in a digital world. MIS Quarterly, 41(1), 223-238.

Pigni, F., Piccoli, G., \& Watson, R. (2016). Digital data streams. California Management Review, 58(3), 5-25.

Rubera, G., \& Kirca, A. H. (2012). Firm innovativeness and its performance outcomes: A meta-analytic review and theoretical integration. Journal of Marketing, 76(3), 130-147.

Rust, R. T., \& Huang, M. H. (2014). The service revolution and the transformation of marketing science. Marketing Science, 33(2), 206-221.

Rust, R, T., \& Oliver, R, W. (2000). The real-time service product: Conquering customer time and space. In: Fitzsimmons, J., \& Fitzsimmons, M. J. (1999). New service development: Creating memorable experiences. Sage Publications.

Rutz, O. J., \& Watson, G. F. (2019). Endogeneity and marketing strategy research: An overview. Journal of the Academy of Marketing Science, 47(3), 479-498.

Shah, S., Horne, A., \& Capellà, J. (2012). Good data Won't guarantee good decisions. Harvard Business Review, 90(4), 23-25.

Sleep, S., Hulland, J., \& Gooner, R. A. (2019). The data hierarchy: Factors influencing the adoption and implementation of datadriven decision making. AMS Review, 9(3-4), 230-248.

Sorescu, A. (2017). Data-driven business model innovation. Journal of Product Innovation Management, 34(5), 691-696.

Strong, D. M., Volkoff, O., Johnson, S. A., Pelletier, L. R., Tulu, B., BarOn, I., Trudel, J., \& Garber, L. (2014). A theory of organization-
EHR affordance actualization. Journal of the Association for Information Systems, 15(2), 53-85.

Tambe, P. (2014). Big data investment, skills, and firm value. Management Science, 60(6), 1452-1469.

Troilo, G., De Luca, L. M., \& Guenzi, P. (2017). Linking data-rich environments with service innovation in incumbent firms: A conceptual framework and research propositions. Journal of Product Innovation Management, 34(5), 617-639.

Volkoff, O., \& Strong, D, M. (2018). Affordance theory and how to use it in IS research. In: The Routledge Companion to Management Information Systems, 232-245. Routledge.

Voss, G. B., \& Voss, Z. G. (2013). Strategic ambidexterity in small and medium-sized enterprises: Implementing exploration and exploitation in product and market domains. Organization Science, 24(5), 1291-1600.

Wamba, S. F., Gunasekaran, A., Akter, S., Ren, S. J. F., Dubey, R., \& Childe, S. J. (2017). Big data analytics and firm performance: Effects of dynamic capabilities. Journal of Business Research, $70(1), 356-365$.

Wang, R., Gupta, A., \& Grewal, R. (2017). Mobility of top marketing and sales executives in business-to-business markets: A social network perspective. Journal of Marketing Research, 54(4), 650-670.

Wedel, M., \& Kannan, P. K. (2016). Marketing analytics for data-rich environments. Journal of Marketing, 80(6), 97-121.

Zammuto, R. F., Griffith, T. L., Majchrzak, A., Dougherty, D. J., \& Faraj, S. (2007). Information technology and the changing fabric of organization. Organization Science, 18(5), 749-762.

Zuboff, S. (2015). Big other: Surveillance capitalism and the prospects of an information civilization. Journal of Information Technology, 30(1), 75-89.

Publisher's note Springer Nature remains neutral with regard to jurisdictional claims in published maps and institutional affiliations. 